\title{
Effect of layer length on deflection in sandwich beams
}

\author{
Muthanna A. Abbu' ${ }^{1}$ - Riyadh AL-Ameri ${ }^{2}$
}

Received: 30 September 2016/Accepted: 16 May 2017/Published online: 29 May 2017

(c) The Author(s) 2017. This article is an open access publication

\begin{abstract}
A theoretical study has been carried out on sandwich beams strengthened mechanically by two external steel plates attached to their tension and compression sides with so-called "shear connectors ". This study is based on the individual behaviour of each component of the composite sandwich section (i.e. reinforced concrete beam and upper steel plate and lower steel plate). The approach has been developed to simulate the behaviour of such beams, and is based on neglecting the separation between the three layers; i.e., the deflections are equal in each element through the same section. The differential equations reached were solved analytically. Deflection was calculated by using the approach for several beams, tested in two series, and close agreements were obtained with the experimental values. Furthermore, the interaction efficiency between the three elements in a composite sandwich beam has been considered thoroughly, from which the effect of some parameters, such as plate length upon the behaviour of such beams, were studied.
\end{abstract}

Keywords Multilayer beam - Sandwich beam . Strengthening beam with steel plate Interlayer slip

Muthanna A. Abbu

abbu@ntu.edu.iq; muthanna.abbu@gmail.com

1 Building and Construction Engineering Techniques, Engineering Technical College, Northern Technical University, Mosul, Iraq

2 School of Engineering, Deakin University, Geelong, Australia

\section{Introduction}

In structural engineering, the maintenance, repair and upgrading of structures is just as important and technical as the design and construction of new structures. Upgrading usually involves strengthening of an existing structure which was found unsatisfactory due to poor performance under service loading or inadequate strength. Strengthening deficient or critical members may involve adding new material to the existing member. Usually, the analysis of layered beam systems is based on the assumption of rigid interconnection.

Yang et al. (2015a, b) submitted that a strengthened beam consists of two layers of epoxy-bonded, pre-stressed steel plates and the reinforced concrete (RC) beam sandwiched in between. The bonding-enclosed and pre-stressed $\mathrm{U}$-shaped steel jackets were applied at the beam sides.

Itani et al. (1981) produced an experimental study to verify the theoretical analysis of a diaphragm in a satisfactory manner. It was seen that the theoretical analysis of the diaphragm overestimated strains and deflections because it did not account for the effects of joists in the diaphragm, and the presence of discontinuities in layers of a glued lumber diaphragm does not have considerable significance.

Roberts and Haji-Kazemi (1989) performed tests on 18 rectangular, RC beams having steel plates attached mechanically to the tension face of the beams by expanding bolts, which were either cast-in during manufacture of the beams or drilled and fixed via a torque control process after curing. The parameters considered are the thickness of plates ( 2 and $4 \mathrm{~mm}$ ) and the bolt length. Test results showed a significant improvement in the stiffness of the plated beams and all beams exhibited a ductile failure followed by crushing of the concrete in the compression 
zone. The mode of failure for beams with relatively thick steel plates $(4 \mathrm{~mm})$ was invariably characterized by shearing off one or more of the bolts near the plate ends. The length of the bolts and method of fixing the steel plates, in which connectors were driven either during concrete casting or after hardening, had little influence on the ultimate strength.

Ovigne et al. (2003) presented an analytical model of a beam with open cracks and external strengthening which is able to predict its modal schema components (natural frequencies and mode shapes).

Abtan (1997) investigated the behaviour of reinforced concrete beams with external steel plates, in which a series of 12 tests was carried out on under-reinforced concrete beams strengthened mechanically with plates of different length, width and thickness. Two beams out of 12 were without steel plates as controlling beams. One beam was preloaded to approximately $60 \%$ of its ultimate strength before attaching the steel plate. The test showed that the external reinforcement (plates) increased the flexural stiffness of the beam at all stages of loading, and consequently reduced the deflection at corresponding loads. Less deflection was obtained by increasing the length and area of the plate. Also, a correlation was recorded between the maximum slip and the central deflection of the plated beam and the maximum slip is affected by the area and length of the steel plate.

Aykac et al. (2012) suggested investigating the influence using perforated steel plates instead of solid steel plates on the ductility of reinforced concrete beams. Push-out tests conducted by Han et al. (2015) to investigate the static behavior of a steel and rubber-filled concrete composite beam with different ratios of rubber mixed with concrete and studs. The results of the experimental investigations show that large studs lead to a higher ultimate strength but worse ductility in normal concrete.

Abbu (2003) presented a theoretical study of reinforced concrete beams strengthened mechanically by external steel plates attached to their tension side with so-called "shear connectors". This study was based on the individual behaviour of each component of the composite section (i.e. reinforced concrete beam and external steel plate). Two approaches were developed to simulate the behaviour of such beams. The first approach was based on neglecting the separation between the two elements (i.e. the deflections are equal in both (elements). The differential equation obtained was solved analytically. The second approach takes both the slip and the separation between the two elements into account. The derived differential equations were solved numerically using the finite difference representation. Slip, deflections, stress and strain were calculated by using both approaches for several beams, tested previously. Close agreements were obtained with the experimental values for different thicknesses and widths of the strengthening plates.

Demir et al. (2014) produced strengthen cracked beams with prefabricated RC U cross-sectional plates. The damaged beams were repaired with epoxy-based glue. The repaired beams were strengthened using prefabricated plates.

The failure mode and ultimate load-bearing capacity of the steel concrete-steel composite beam under the fourpoint-bend loading was investigated by Zou et al. (2016). The load-displacement curves and results of failure mode were in good agreement with experiments. A finite element (FE) model was presented by Lezgy-Nazargah and Kafi (2015) for the analysis of composite steel-concrete beams based on a refined high-order theory. The employed theory satisfied all the kinematic and stress continuity conditions at the layer interfaces and considered the effects of the transverse normal stress and transverse flexibility.

The flexural vibration differential equations and boundary conditions of the steel-concrete composite beam (SCCB) with comprehensive consideration of the influences of the shear deformation, interface slip and longitudinal inertia of motion were derived by Zhou et al. (2016). The analytical natural frequencies of flexural vibration were compared with available results previously observed by the experiments; the results were calculated by the FE model and other similar beam theories available in the open literatures. The comparison showed that the calculation results of the analytical and Timoshenko models had good agreement with the results of the experimental test and FE model.

Yang et al. (2015a, b) introduced a new kind of partially precast or prefabricated, castellated, steel-reinforced, concrete beam, which is abbreviated here as CPSRC beam. This kind of CPSRC beam is composed of a precast outer part and a cast-in-place inner part. The precast outer part is composed of an encased, castellated steel shape, reinforcement bars and high-performance concrete. Simplified formulas were proposed by Yang et al. (2015a, b) to calculate the prestress and the ultimate capacities of the strengthened beams. The accuracy of the formulas was verified by the experimental results.

Jones et al. (1982) studied the behaviour of reinforced concrete beams $(155 \times 225 \times 2500 \mathrm{~mm})$ externally reinforced by steel plates glued to their tension face. The variables considered were the thickness of plates, number of plate layers, lapping technique, preloading and glue thickness (see Fig. 1). The effects of these variables upon the deformation characteristics and ultimate strength of the beams were studied. Test results indicated that the addition of glued plates to concrete beams substantially increases their flexural stiffness, reduced structural deformations at all load levels, and contributed to the ultimate flexural 
capacity. However, lapped plates, precracking and variable glue thickness had no effect on the structural behaviour of the beams. Beams with multiple layers of plates behave almost similar to beams with single plates of the same total sectional area. The beams strengthened with thick plates (3 and $6 \mathrm{~mm}$ ) fail led by the sudden separation of the plate ends together with the concrete cover, before reaching their ultimate load.

In the present study, primary attention is focused on developing representative numerical models for a sandwich beam. To achieve this aim, several analytical models of a laboratory specimen are developed using different approaches available within programming procedure. A good representation for external plates is used. Rigid link elements extended the models with full interaction composition. Modelling details and results of different models are presented. The results acquired from numerical models are assessed against test results, and the performance of the models is detailed. In addition, a study of the effect of layer length on the behaviour of the sandwich beam is submitted. This effect caused by reduction deflection in longitudinal directions with several different percentages is also submitted.

\section{Shear distributed load}

In question is an element comprised of three layers, an upper steel plate, concrete and a lower steel plate. Consider, a transformed concrete section for which moment of inertia, modulus of elasticity and area are denoted by $\left(l_{\mathrm{co}}\right)$, $\left(E_{\mathrm{co}}\right)$ and $\left(A_{\mathrm{co}}\right)$ respectively. The two interfaces' shear distributed forces are $\left(q_{1}, q_{2}\right)$ and the tension peeling forces are $\left(F_{1}, F_{2}\right)$ between the upper steel plate and concrete also between the concrete and the lower steel plate, respectively. The longitudinal equilibrium of either the concrete beam or steel plates gives (see Fig. 1):

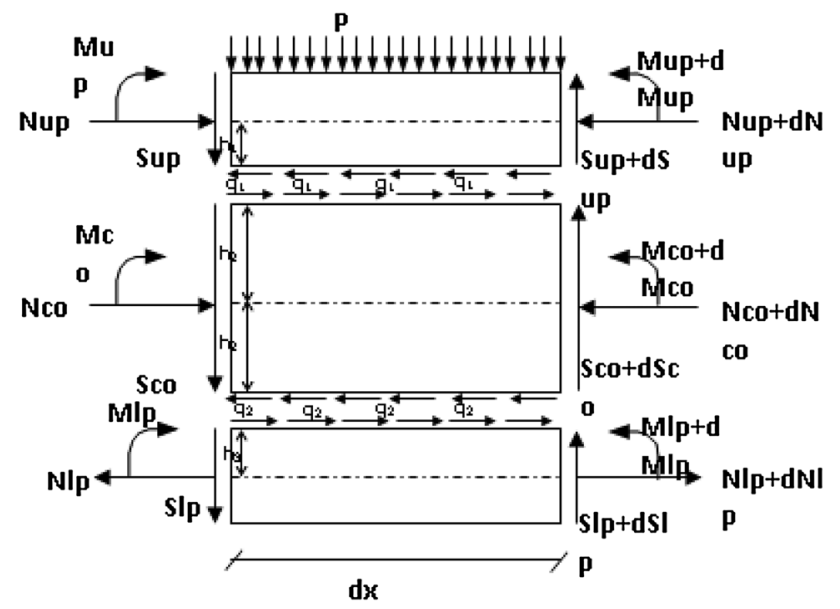

Fig. 1 Element from three layers with forces
For upper elementary

$N_{\text {up }, \mathrm{x}}=-q_{1}$.

For middle element

$N_{\mathrm{up}, \mathrm{x}}-N_{\mathrm{lp}, \mathrm{x}}=q_{2}-q_{1}$.

For lower elementary

$N_{\mathrm{lp}, \mathrm{x}}=-q_{2}$.

Equilibrium of the vertical forces implies:

$S_{\text {up }, \mathrm{x}}=P+F_{1}$,

$S_{\mathrm{co}, \mathrm{x}}=F_{1}-F_{2}$,

$S_{\mathrm{l}, \mathrm{x}}=-F_{2}$.

The equilibrium of moments of the three elements about their centroids will give:

$M_{\mathrm{up}, \mathrm{x}}=-S_{\mathrm{up}}-N_{\mathrm{up}, \mathrm{x}} \cdot h_{1}$

$M_{\mathrm{co}, \mathrm{x}}=-S_{\mathrm{co}}-N_{\mathrm{up}, \mathrm{x}} \cdot d_{1}-N_{\mathrm{lp}, \mathrm{x}} \cdot d_{2}$,

$M_{\mathrm{lp}, \mathrm{x}}=-S_{\mathrm{lp}}-N_{\mathrm{lp}, \mathrm{x}} \cdot h_{3}$.

where: $d_{1}=h_{1}+h_{2} ; d_{2}=h_{2}+h_{3}$.

Furthermore, the composite FE satisfies the compatibility requirement

$q_{1}=\frac{U_{\mathrm{sc}} \cdot K}{\mathrm{~s}}$,

$q_{2}=\frac{U_{\mathrm{cs}} \cdot K}{\mathrm{~s}}$,

where $\left(U_{\mathrm{sc}}, U_{\mathrm{cs}}\right)$ is the slip at the interface between the upper plate and concrete and concrete and lower plate, respectively, $(K)$ is shear stiffness of the connectors, and $(S)$ is the spacing between the connectors. Differentiate Eqs. (10 and 11) once with respect to $(x)$ will give,

$q_{1, \mathrm{x}}=U_{\mathrm{sc}, \mathrm{x}} \cdot K_{\mathrm{s}}$,

$q_{2, \mathrm{x}}=U_{\mathrm{cs}, \mathrm{x}} \cdot K_{\mathrm{s}}$,

where,

$K_{\mathrm{s}}=K / S$.

While, $\left(U_{\mathrm{sc}, \mathrm{x}}\right.$ and $\left.U_{\mathrm{cs}, \mathrm{x}}\right)$ is defined as the slip strain at the interfaces between the concrete and two steel plates, which equals to,

$U_{\mathrm{sc}, \mathrm{x}}=\varepsilon_{\mathrm{up}}-\varepsilon_{\mathrm{co}}$,

$U_{\mathrm{cs}, \mathrm{x}}=\varepsilon_{\mathrm{co}}-\varepsilon_{\mathrm{lp}}$,

where, $\left(\varepsilon_{\mathrm{up}}\right)$ represents the strain at the bottom of the upper steel plate, and $\left(\varepsilon_{\mathrm{co}}\right)$ is the strain of concrete beam (top and bottom), and ( $\left.\varepsilon_{\mathrm{lp}}\right)$ is the strain at the top of the lower steel plate. Assuming equal curvature for the three elements, we have:

$W_{\mathrm{xx}}=W_{\mathrm{up}, \mathrm{xx}}=W_{\mathrm{co}, \mathrm{xx}}=W_{\mathrm{lp}, \mathrm{xx}}$. 
From elastic beam theory:

$$
\begin{aligned}
& W_{\mathrm{up}, \mathrm{xx}}=M_{\mathrm{up}} / E_{\mathrm{up}} \cdot I_{\mathrm{up}}, \\
& W_{\mathrm{co}, \mathrm{xx}}=M_{\mathrm{co}} / E_{\mathrm{co}} \cdot I_{\mathrm{co}}, \\
& W_{\mathrm{lp}, \mathrm{xx}}=M_{\mathrm{lp}} / E_{\mathrm{lp}} \cdot I_{\mathrm{lp}},
\end{aligned}
$$

we can define $\varepsilon_{\text {up }}, \varepsilon_{\text {co }}$ and $\varepsilon_{\mathrm{lp}}$ as below:

$\varepsilon_{\text {up }}=h_{\text {up }} \cdot \frac{M_{\text {up }}}{E_{\text {up }} \cdot I_{\text {up }}}-\frac{N}{E_{\text {up }} \cdot A_{\text {up }}}$,

$\varepsilon_{\mathrm{co}}=h_{\mathrm{co}} \cdot \frac{M_{\mathrm{co}}}{E_{\mathrm{co}} \cdot I_{\mathrm{co}}}-\frac{N}{E_{\mathrm{co}} \cdot A_{\mathrm{co}}}$,

$\varepsilon_{\mathrm{lp}}=h_{\mathrm{lp}} \cdot \frac{M_{\mathrm{lp}}}{E_{\mathrm{lp}} \cdot I_{\mathrm{lp}}}-\frac{N}{E_{\mathrm{lp}} \cdot A_{\mathrm{lp}}}$.

Combining Eqs. (10), (12), (21) and (22), the following equation can be obtained:

$\frac{q_{1, \mathrm{x}}}{K_{\mathrm{s}}}=\frac{h_{\mathrm{up}} \cdot M_{\mathrm{up}}}{E_{\mathrm{up}} \cdot I_{\mathrm{up}}}+\frac{h_{\mathrm{co}} \cdot M_{\mathrm{co}}}{E_{\mathrm{co}} \cdot I_{\mathrm{co}}}-N\left[\frac{h_{\mathrm{up}}}{E_{\mathrm{up}} \cdot A_{\mathrm{up}}}+\frac{h_{\mathrm{co}}}{E_{\mathrm{co}} \cdot A_{\mathrm{co}}}\right]$.

And combining Eqs. (11), (13), (22) and (23), the following equation can be obtained:

$\frac{q_{2, \mathrm{x}}}{K_{\mathrm{s}}}=\frac{h_{\mathrm{lp}} \cdot M_{\mathrm{lp}}}{E_{\mathrm{lp}} \cdot I_{\mathrm{lp}}}+\frac{h_{c o} \cdot M_{\mathrm{co}}}{E_{\mathrm{co}} \cdot I_{\mathrm{co}}}-N\left[\frac{h_{\mathrm{lp}}}{E_{\mathrm{lp}} \cdot A_{\mathrm{lp}}}+\frac{h_{\mathrm{co}}}{E_{\mathrm{co}} \cdot A_{\mathrm{co}}}\right]$.

Differentiating the Eqs. (24) and (25) once with respect to $(x)$ and substituting the value of $\left(N_{\mathrm{x}}\right),\left(M_{\mathrm{up}}, M_{\mathrm{co}}\right)$ and $\left(M_{1 \mathrm{p}}\right)$ from Eqs. $(1),(7,8)$ and $(9)$, respectively, Eqs. (24) and (25) become:

$$
\begin{aligned}
q_{1, \mathrm{xx}}= & q \cdot K_{\mathrm{s}}\left[\frac{h_{\mathrm{up}}^{2}}{E_{\mathrm{up}} \cdot I_{\mathrm{up}}}+\frac{1}{E_{\mathrm{up}} \cdot A_{\mathrm{up}}}+\frac{h_{\mathrm{co}}^{2}}{E_{\mathrm{co}} \cdot I_{\mathrm{co}}}+\frac{1}{E_{\mathrm{co} \cdot A_{\mathrm{co}}}}\right] \\
& -\frac{h_{\mathrm{up}} \cdot S_{\mathrm{up}} \cdot K_{\mathrm{s}}}{E_{\mathrm{up}} \cdot I_{\mathrm{up}}}-\frac{h_{\mathrm{co}} \cdot S_{\mathrm{co}} \cdot K_{\mathrm{s}}}{E_{\mathrm{co}} \cdot I_{\mathrm{co}}} \\
q_{2, \mathrm{xx}}= & q \cdot K_{\mathrm{s}}\left[\frac{h_{\mathrm{lp}}^{2}}{E_{\mathrm{lp}} \cdot I_{\mathrm{lp}}}+\frac{1}{E_{\mathrm{lp}} \cdot A_{\mathrm{lp}}}+\frac{h_{\mathrm{co}}^{2}}{E_{\mathrm{co}} \cdot I_{\mathrm{co}}}+\frac{1}{E_{\mathrm{co} \cdot A_{\mathrm{co}}}}\right] \\
& -\frac{h_{\mathrm{lp}} \cdot S_{\mathrm{lp}} \cdot K_{s}}{E_{\mathrm{lp}} \cdot I_{\mathrm{lp}}}-\frac{h_{\mathrm{co}} \cdot S_{\mathrm{co}} \cdot K_{\mathrm{s}}}{E_{\mathrm{co}} \cdot I_{\mathrm{co}}} .
\end{aligned}
$$

And if we note Fig. 1 we can assume that the shear due to external loads (total shear TS) is carried by concrete only, so that:

$S_{\text {up }}=0$,

$S_{\mathrm{co}}=\mathrm{TS}$.

Along the concrete beam

$$
S_{\mathrm{lp}}=0 \text {. }
$$

\section{Assume}

$V_{1}=\omega_{1} \cdot \mathrm{Ks}$,
$V_{2}=\omega_{2} . \mathrm{Ks}$

where

$\omega_{1}=\frac{h_{\mathrm{up}}^{2}}{E_{\mathrm{up}} \cdot I_{\mathrm{up}}}+\frac{1}{E_{\mathrm{up}} \cdot A_{\mathrm{up}}}+\frac{h_{\mathrm{co}}^{2}}{E_{\mathrm{co}} \cdot I_{\mathrm{co}}}+\frac{1}{E_{\mathrm{co}} \cdot A_{\mathrm{co}}}$,

$\omega_{2}=\frac{h_{\mathrm{lp}}^{2}}{E_{\mathrm{lp}} \cdot I_{\mathrm{lp}}}+\frac{1}{E_{\mathrm{lp}} \cdot A_{\mathrm{lp}}}+\frac{h_{\mathrm{co}}^{2}}{E_{\mathrm{co}} \cdot I_{\mathrm{co}}}+\frac{1}{E_{\mathrm{co} .} A_{\mathrm{co}}}$.

By using Eqs. $(28,29,32)$ and (33) and neglecting the effect of the peeling forces on the deflection of the concrete beam from the two sides, Eq. (26) becomes:

$q_{1, \mathrm{xx}}-V_{1} \cdot q_{1}+\frac{h_{\mathrm{co}} \cdot K_{\mathrm{s}}}{E_{\mathrm{co}} \cdot I_{\mathrm{co}}} . \mathrm{TS}=0$.

Also, by using Eqs. (29, 30, 32) and (34), Eq. (27) becomes:

$q_{2, \mathrm{xx}}-V_{2} \cdot q_{2}+\frac{h_{\mathrm{co}} \cdot K_{\mathrm{s}}}{E_{\mathrm{co}} \cdot I_{\mathrm{co}}} . \mathrm{TS}=0$.

Equations (35) and (36) represent the general differential equations for shear distributed forces.

\section{Solution for uniformly distributed load}

Consider a simply supported beam of span $(L)$ with plastic layer material (e.g. concrete) strengthened mechanically with upper and lower elastic layer materials, of length $\left(l_{\text {up }}\right.$ and $l_{1 \mathrm{p}}$ ), respectively, and subjected to a uniformly distributed load $(p)$. The distance $(x)$ is measured from the beginning of the lower steel plate. The shear force, (TS), due to external load at a distance $(x)$ from the left end of the lower steel plate is:

$\mathrm{TS}=p \cdot\left(a+x-1_{\mathrm{co}} / 2\right)$,

where $(a)$ is the distance from the support of the nearer end of the lower steel plate. Then, the general solution of the differential Eqs. (26) and (27) can be obtained as, see Fig. 2:

$q_{1}=A_{1} \cdot \cosh \zeta x+A_{2} \cdot \operatorname{shin} \zeta x+\frac{h_{\mathrm{co}} \cdot \rho}{E_{\mathrm{co}} \cdot I_{\mathrm{co}} \cdot \omega_{1}}\left(x-\left(l_{u p} / 2+b\right)\right)$,

$q_{2}=A_{3} \cdot \cosh \zeta x+A_{4} \cdot \operatorname{shin} \zeta x+\frac{h_{\mathrm{co}} \cdot \rho}{E_{\mathrm{co}} \cdot I_{\mathrm{co}} \cdot \omega_{2}}\left(x-l_{\mathrm{lp}} / 2\right)$.

Noting that $b$ is the distance from the end of $(a)$ to the beginning of the upper steel plate and $\left(A_{1}\right),\left(A_{2}\right)$ and $\left(A_{3}\right)$, $\left(A_{4}\right)$ are constants of integration, and can be obtained after satisfying the boundary conditions, which are at $x=0$ 
$q_{2, x}=\frac{M_{\mathrm{co}} \cdot K_{\mathrm{s}} \cdot h_{\mathrm{co}}}{E_{\mathrm{co}} \cdot I_{\mathrm{co}}}$

At $x=b$

$q_{1, x}=\frac{M_{\mathrm{co}} \cdot K_{\mathrm{s}} \cdot h_{\mathrm{co}}}{E_{\mathrm{co}} \cdot I_{\mathrm{co}}}$,

where

$M_{\mathrm{co}}=P . a\left(l_{\mathrm{co}}-a\right) / 2$,

At $x=11 \mathrm{p} / 2$,

$q_{1}=0$,

And at $x=l_{\mathrm{up}} / 2$,

$q_{2}=0$

Then,

$A_{1}=-A_{2} \cdot \tanh \zeta\left(\frac{. l_{\mathrm{up}}}{2}+b\right)$,

$A_{2}=\frac{h_{\mathrm{co}} \cdot \rho}{E_{\mathrm{co}} \cdot I_{\mathrm{co}}} \cdot\left(\frac{K_{s} \cdot a \cdot\left(l_{\mathrm{co}}-a\right)}{2 . \zeta}-\frac{1}{\zeta \cdot \omega_{1}}\right)$,

$A_{3}=-A_{4} \cdot \tanh \zeta\left(\frac{. l_{\mathrm{lp}}}{2}\right)$,

$A_{4}=\frac{h_{c o} \cdot \rho}{E_{\mathrm{co}} \cdot I_{\mathrm{co}}} \cdot\left(\frac{K_{s} \cdot a \cdot\left(l_{\mathrm{co}}-a\right)}{2 . \zeta}-\frac{1}{\zeta \cdot \omega_{2}}\right)$.

Therefore, the particular solution for the basic differential equation will become:

$$
\begin{aligned}
q_{1}= & \frac{\rho \cdot h_{\mathrm{co}}}{E_{\mathrm{co}} \cdot I_{\mathrm{co}}}\left[\left(\frac{K_{s} \cdot a \cdot\left(l_{c o}-a\right)}{\zeta \cdot 2}-\frac{1}{\zeta \cdot \omega_{1}}\right) .\right. \\
& \left.\left(\sinh \zeta x-\tanh \zeta \cdot\left(\frac{l_{\mathrm{up}}}{2}+b\right) \cosh \zeta x\right)+\frac{x-\left(l_{\mathrm{up}} / 2+b\right)}{\omega_{1}}\right], \\
q_{2}= & \frac{\rho \cdot h_{\mathrm{co}}}{E_{\mathrm{co}} \cdot I_{\mathrm{co}}}\left[\left(\frac{K_{\mathrm{s}} \cdot a \cdot\left(l_{\mathrm{co}}-a\right)}{\zeta \cdot 2}-\frac{1}{\zeta \cdot \omega_{2}}\right) .\right. \\
& \left.\left(\sinh \zeta x-\tanh \frac{\zeta \cdot l_{\mathrm{lp}}}{2} \cosh \zeta x\right)+\frac{x-l_{\mathrm{lp}} / 2}{\omega_{2}}\right] .
\end{aligned}
$$

\section{Prediction of deflection}

The value of deflection is one of the important parameters in the service life of structures, which should be limited to satisfy an acceptable behaviour. Therefore, prediction of deflection is an important step in design and checking the performance of structural members. In order to arrive at an expression for the deflection of the sandwich beam, summing Eqs. $(7,8)$ and $(9)$ gives:

$M_{\mathrm{co}, \mathrm{x}}+M_{\mathrm{up}, \mathrm{x}}+M_{\mathrm{lp}, \mathrm{x}}=d_{1} \cdot q_{1}-d_{2} \cdot q_{2}-\mathrm{TS}$,

where $d_{1}=h_{1}+h_{2}$ and $d_{2}=h_{2}+h_{3}$

Also, from Eqs. $(18,19)$ and $(20),\left(M_{\mathrm{co}}, M_{\mathrm{up}}\right)$ and $\left(M_{\mathrm{lp}}\right)$ can be obtained by differentiating these equations once with respect to $(x)$ :

$\mathrm{M}_{\mathrm{up}, \mathrm{x}}=W_{, \mathrm{xxx} .} E_{\mathrm{up}} \cdot I_{\mathrm{up}}$,

$\mathrm{M}_{\mathrm{co}, \mathrm{x}}=W_{, \mathrm{xxx} .} E_{\mathrm{co}} \cdot I_{\mathrm{co}}$,

$M_{\mathrm{lp}, \mathrm{x}}=W_{, \mathrm{xxx}} \cdot E_{\mathrm{lp}} \cdot I_{\mathrm{lp}}$.

Substituting the values of $\left(M_{\mathrm{up}, \mathrm{x}}, M_{\mathrm{co}, \mathrm{x}}\right)$ and $\left(M_{\mathrm{lp}, \mathrm{x}}\right)$ in Eq. (51) and simplifying will give:

$W_{\mathrm{xxx}}=\frac{1}{H_{0}}\left(d_{1} \cdot q_{1}+d_{2} \cdot q_{2}-\mathrm{TS}\right)$,

where

$H_{0}=E_{\mathrm{co}} \cdot I_{\mathrm{co}}+E_{\mathrm{up}} \cdot I_{\mathrm{up}}+E_{\mathrm{lp}} \cdot I_{\mathrm{lp}}$.

Differentiating Eq. (55), once with respect to (x), will arrive at the general expression for deflection as:

$W_{\mathrm{xxxx}}=\frac{1}{H_{0}}\left(d_{1} \cdot q_{1, \mathrm{x}}+d_{2} \cdot q_{2, \mathrm{x}}-\mathrm{TS}_{\mathrm{x}}\right)$.

From Eq. (57) above, the deflection (w) of the sandwich beams with unequal lengths can be calculated by integrating four times with respect to $(x)$. The four constants of integration can be determined by applying the boundary condition for every case of loading.

\section{Solution for the case of uniformly distributed load}

For a simply supported beam, the shear force (TS) at a distance $(x)$ from the left end of steel plate is given by Eq. (37), then $\left(\mathrm{TS}_{, \mathrm{x}}\right)$ is,

$T \mathrm{~s}_{, \mathrm{X}}=P$.

Substituting for $\left(\mathrm{TS}_{, \mathrm{x}}\right)$ and $\left(\mathrm{q}_{1, \mathrm{x}}\right.$ and $\left.\mathrm{q}_{2, \mathrm{x}}\right)$ from Eqs. (58) and (49 and 50), respectively, into Eq. (57), will give the general solution for this case as:

$$
\begin{aligned}
& W_{, \mathrm{Xxxx}}=\frac{1}{H_{0}} \\
& \times\left[\begin{array}{r}
\zeta \cdot d_{1}\left(A_{1} \cdot \sinh \zeta \cdot x+A_{2} \cdot \cosh \zeta \cdot x\right)+\zeta \cdot d_{2}\left(A_{3} \sinh \zeta \cdot x+A_{4} \cdot \cosh \zeta \cdot x\right) \\
+P \cdot\left(\frac{h_{\mathrm{co}} \cdot d_{1}}{E_{\mathrm{co}} \cdot I_{\mathrm{co}} \cdot \omega_{1}}+\frac{h_{c o} \cdot d_{2}}{E_{\mathrm{co}} \cdot I_{\mathrm{co}} \cdot \omega_{2}}-1\right)
\end{array}\right] .
\end{aligned}
$$

By integrating Eq. (59) four times with respect to (x), the final form of $(w)$ can be as: 
$W=\left[\begin{array}{l}\frac{. d_{1}}{\zeta^{3}}\left(A_{1} \cdot \sinh \zeta \cdot x+A_{2} \cdot \cosh \zeta \cdot x\right)+\frac{. d_{2}}{\zeta^{3}}\left(A_{3} \sinh \zeta \cdot x+A_{4} \cdot \cosh \zeta \cdot x\right) \\ +P \cdot \frac{X^{4}}{24}\left(\frac{h_{\mathrm{co}} \cdot d_{1}}{E_{\mathrm{co}} \cdot I_{\mathrm{co}} \cdot \omega_{1}}+\frac{h_{\mathrm{co}} \cdot d_{2}}{E_{\mathrm{co}} \cdot I_{\mathrm{co}} \cdot \omega_{2}}-1\right)+C_{1} \cdot \frac{X^{3}}{6}+C_{2} \cdot \frac{X^{2}}{2}+C_{3} \cdot X+C_{4}\end{array}\right]$,

Fig. 2 sandwich beam with uniformly distributed load

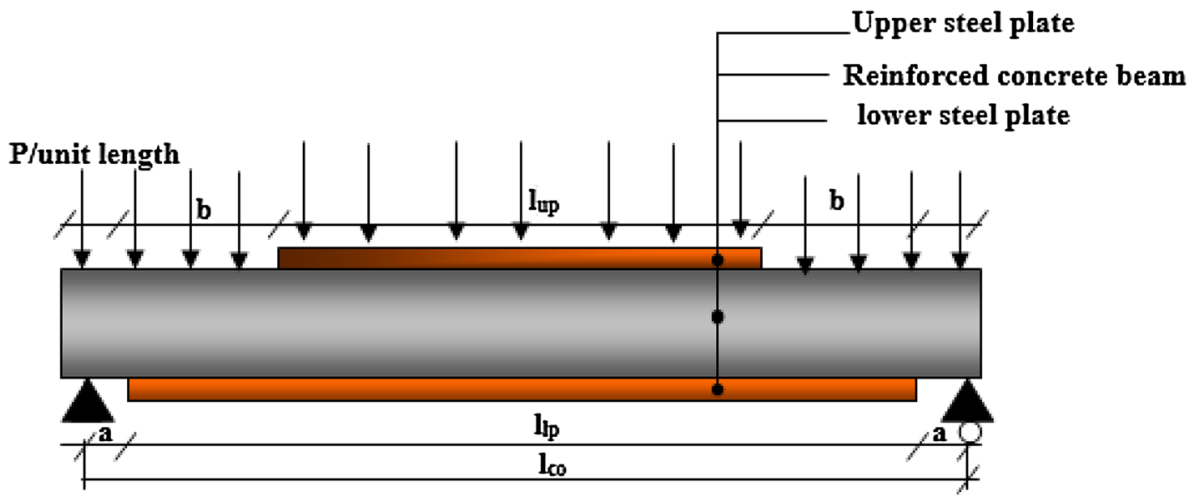

Table 1 Information of Roberts' series

Beam no. $\quad$ Plate thickness (mm) Bolt diameter (mm) $\quad \frac{\text { Compressive strength (Mpa) }}{F_{\mathrm{c}}}$

(a) Details of test beams and concrete properties

\begin{tabular}{ll}
$\mathrm{R} 1$ & \\
$\mathrm{C} 1$ & \\
$\mathrm{C} 2$ & \\
$\mathrm{C} 3$ & 2 \\
$\mathrm{C} 4$ & 4 \\
$\mathrm{D} 1$ & 2 \\
$\mathrm{D} 2$ & 4 \\
$\mathrm{D} 3$ & 2 \\
$\mathrm{D} 4$ & 4 \\
\hline
\end{tabular}

$\begin{array}{ll}- & - \\ 2 & 8 \\ 4 & 8 \\ 2 & 8 \\ 4 & 8 \\ 2 & 8 \\ 4 & 8 \\ 2 & 8 \\ 4 & 8 \\ \end{array}$

-
-

67

37

$8 \quad 54$

$8 \quad 62$

$8 \quad 59$

$8 \quad 72$

$8 \quad 65$

$8 \quad 58$

$8 \quad 62$

62

63

69

64

82

72

63

$8-62$

68

67

Bar diameter (mm)

$0.2 \%$ Proof stress (MPa)

Ultimate stress (MPa)

Elastic modulus $10^{6}(\mathrm{kpa})$

Strain at $0.2 \%$ proof

(b) Average properties of conventional steel reinforcement

\begin{tabular}{|c|c|c|c|c|}
\hline 8 & 487 & 649 & 206 & 0.0043 \\
\hline 10 & 473 & 751 & 200 & 0.0043 \\
\hline
\end{tabular}

Plate thickness $(\mathrm{mm})$

$0.2 \%$ Proof stress $(\mathrm{MPa})$

Ultimate stress (MPa)

Elastic modulus $106(\mathrm{kpa})$

Strain at $0.2 \%$ proof

(c) Average properties of steel plate

$\begin{array}{lllll}2 & 280 & 282 & 208 & 0.0034 \\ 4 & 214 & 214 & 200 & 0.0031\end{array}$

All steel plate are $(1750 \mathrm{~mm})$ in length

All space between connectors are $(140 \mathrm{~mm})$ 


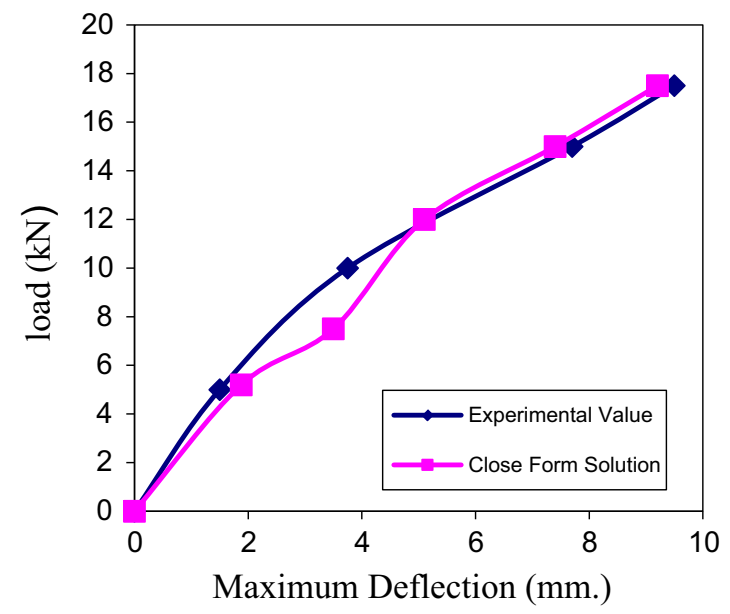

(a)

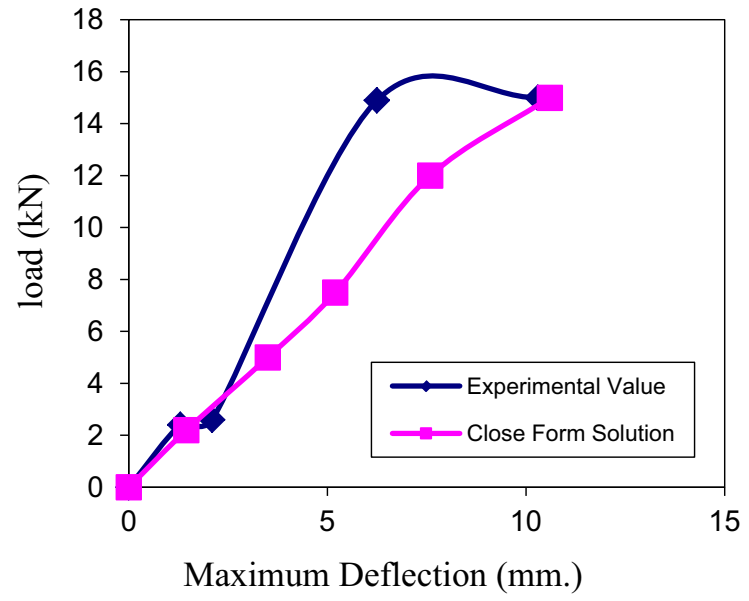

(b)

Fig. 3 Load-deflection curve. a For beam C2. b For beam D1

Table 2 Information of Abtan's series

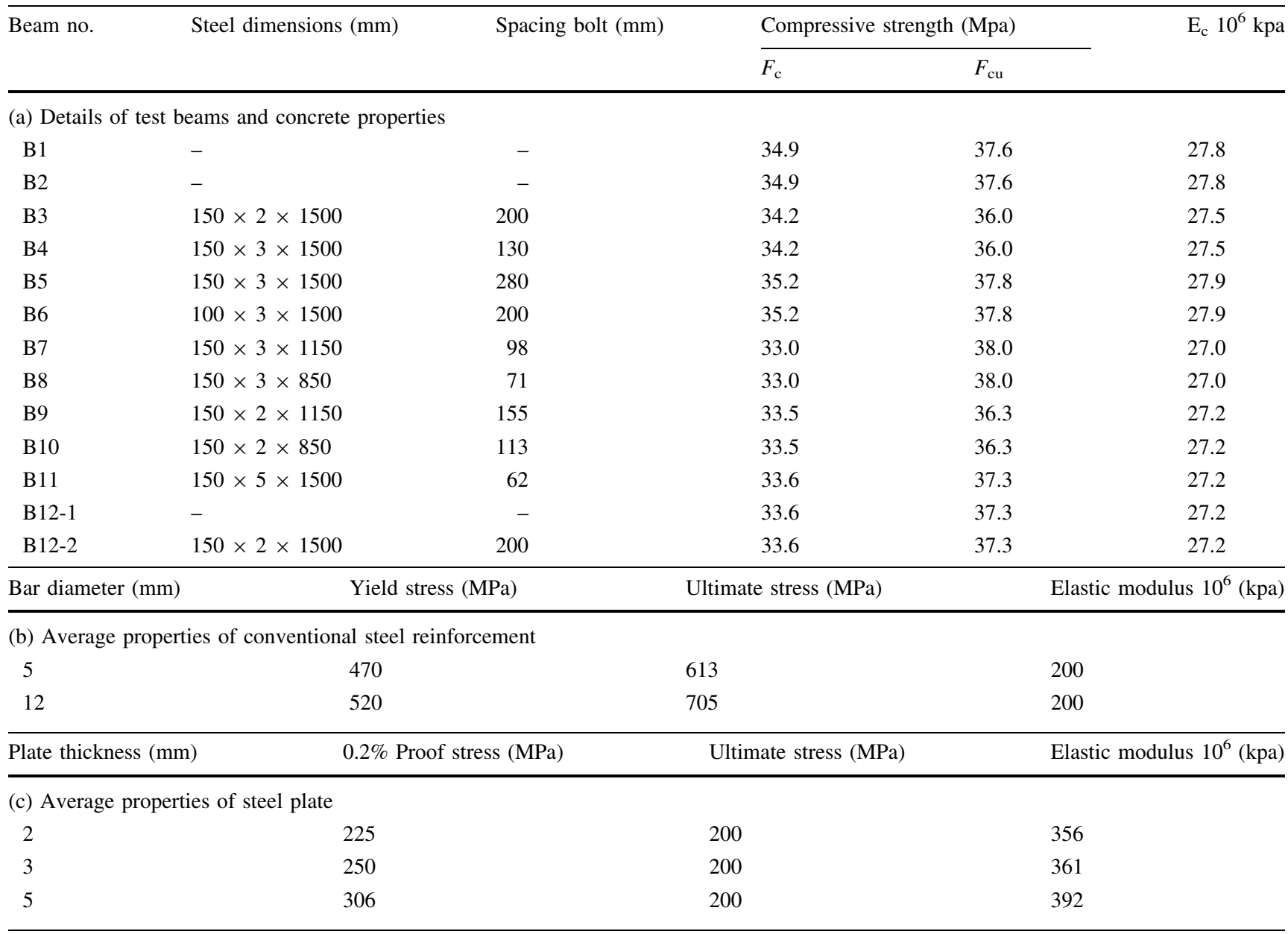


where $\left(A_{1}, A_{2}, A_{3}\right)$ and $\left(A_{4}\right)$ are as defined in earlier Eqs. (45 to 48$)$ and $\left(C_{1}\right)$ to $\left(C_{4}\right)$ are constants of integration, which can be obtained by applying the boundary conditions.

Since the two steel plate not anchored at the supports, the cross-section of the beam will have three different parts: the first part is a reinforced concrete section extending between the support and the end point of the nearest steel plates; the second part is the strengthened section which consists of reinforced concrete and one steel plate, upper or lower (in this case, the lower plate); and the third part is the sandwich beam strengthened with two plates with unequal lengths. Hence, the first part will satisfy the simple bending theory as given below:

$w_{\mathrm{i}, \mathrm{xx}}=\frac{M_{\mathrm{i}}}{E_{\mathrm{co}} \cdot I_{\mathrm{co}}}$,

where $\left(M_{\mathrm{i}}\right)$ and $\left(w_{\mathrm{i}}\right)$ are the moment and curvature of any part of the unplated beam, respectively. $\left(M_{\mathrm{i}}\right)$ is defined as below:

$M_{\mathrm{i}}=R_{a} \cdot x_{0}-\frac{P \cdot x_{0}^{2}}{2}$,

where $\left(R_{\mathrm{a}}\right)$ is the reaction force at support, and $\left(x_{0}\right)$ is the available distance from the support to the nearest end of the plate, and varies from zero to the value of $(a)$.

Hence, the slope and deflection at any point of the unplated part can be obtained from Eq. (61) as below:

$w_{\mathrm{i}, \mathrm{x}}=\frac{1}{E_{\mathrm{co}} \cdot I_{\mathrm{co}}}\left(\frac{R_{a} \cdot x^{2}}{2}-\frac{P . a^{3}}{6}\right)+C_{5}$,

$w_{\mathrm{i}}=\frac{1}{E_{\mathrm{co} .} \cdot I_{\mathrm{co}}}\left(\frac{R_{a} \cdot x^{3}}{6}-\frac{P \cdot a^{4}}{24}\right)+C_{5} \cdot a+C_{6}$.

where $\left(C_{5}\right)$ and $\left(C_{6}\right)$ are constants of integration.

If the deflection of support is zero, then $\left(C_{6}=0\right)$ and the slope and deflection at the free end of the steel plate are:

$w_{\mathrm{i}, \mathrm{x}}=\frac{1}{E_{\mathrm{co}} \cdot I_{\mathrm{co}}}\left(\frac{R_{\mathrm{a}} \cdot a^{2}}{2}-\frac{P \cdot a^{3}}{6}\right)+C_{5}$,

$w_{\mathrm{i}}=\frac{1}{E_{\mathrm{co}} \cdot I_{\mathrm{co}}}\left(\frac{R_{a} \cdot a^{3}}{6}-\frac{P \cdot a^{4}}{24}\right)+C_{5} \cdot a+C_{6}$.

Then, there are five unknown constants that can be defined using the five boundary conditions given below,

At $x=l_{\mathrm{lp}} / 2, \quad W_{, \mathrm{xx}}=0$,

At $x=0, \quad w_{, x x}=w_{\mathrm{i}, x x}$,

At $x=l_{\mathrm{lp}} / 2, \quad W_{, x}=0$,

At $x=0, \quad w_{x}=w_{\mathrm{i}, x}$,

At $x=0, \quad W=w_{\mathrm{I}}$.

Applying the boundary conditions above, the value of constants $\left(C_{1}\right)$ to $\left(C_{5}\right)$ can be obtained.
Table 3 Comparison between the central deflection given by the current model and experimental value

\begin{tabular}{|c|c|c|c|}
\hline $\begin{array}{l}\text { Beam } \\
\text { no. }\end{array}$ & $\begin{array}{l}\text { Experimental } \\
\text { value }(\mathrm{kN})\end{array}$ & $\begin{array}{l}\text { Theoretical value } \\
(\mathrm{kN})\end{array}$ & $\begin{array}{l}\text { Experimental/ } \\
\text { theoretical }\end{array}$ \\
\hline B1 & 2.05 & 2.30 & 0.90 \\
\hline B2 & 2.16 & 2.40 & 0.90 \\
\hline B3 & 2.4 & 2.26 & 1.06 \\
\hline B4 & 2.15 & 2.20 & 0.98 \\
\hline B5 & 2.10 & 2.33 & 0.90 \\
\hline B6 & 2.20 & 2.31 & 0.95 \\
\hline B7 & 2.45 & 2.20 & 1.11 \\
\hline B8 & 3.00 & 3.03 & 0.99 \\
\hline B9 & 2.61 & 2.50 & 1.04 \\
\hline B10 & 2.72 & 2.81 & 0.97 \\
\hline B11 & 2.50 & 2.25 & 1.11 \\
\hline B12-1 & 2.10 & 1.91 & 1.11 \\
\hline B12-2 & 2.50 & 2.41 & 1.04 \\
\hline $\mathrm{R}$ & 9.50 & 8.60 & 1.10 \\
\hline $\mathrm{C} 1$ & 8.60 & 8.47 & 1.02 \\
\hline $\mathrm{C} 2$ & 9.40 & 9.15 & 1.03 \\
\hline C3 & 8.20 & 7.75 & 1.09 \\
\hline $\mathrm{C} 4$ & 7.70 & 8.27 & 0.94 \\
\hline D1 & 11.00 & 10.33 & 1.06 \\
\hline D2 & 11.00 & 11.43 & 0.96 \\
\hline D3 & 8.40 & 7.30 & 1.15 \\
\hline D4 & 11.20 & 10.52 & 1.06 \\
\hline \multicolumn{2}{|c|}{ Mean ratio } & & 1.02 \\
\hline \multicolumn{2}{|c|}{ Standard deviation } & & 0.08 \\
\hline
\end{tabular}

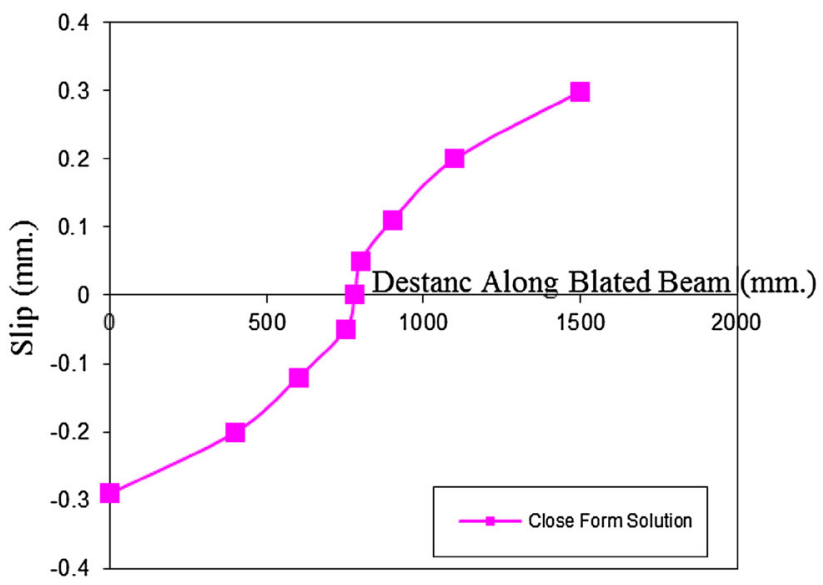

Fig. 4 Slip along the platted part of beam (B6)

\section{Results and comparison with experimental works}

The experimental field investigations of the simply supported sandwich beam are limited due to the high cost of the test model; so, the applications of the solutions are 
Fig. 5 Load-slip curve. a For beam B3. b For beam B4. c For beam B6. d For beam B7. e For beam B8. f For beam B9

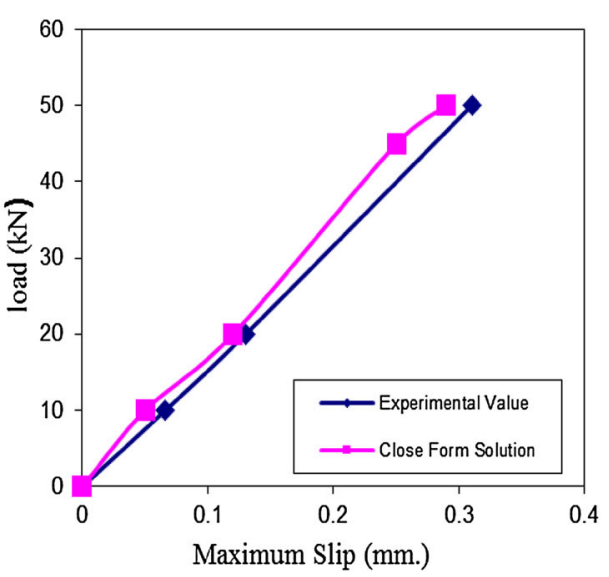

(a)

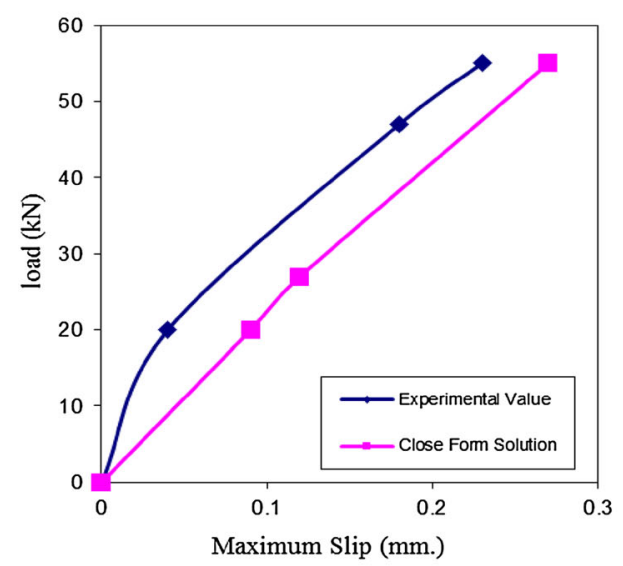

(c)

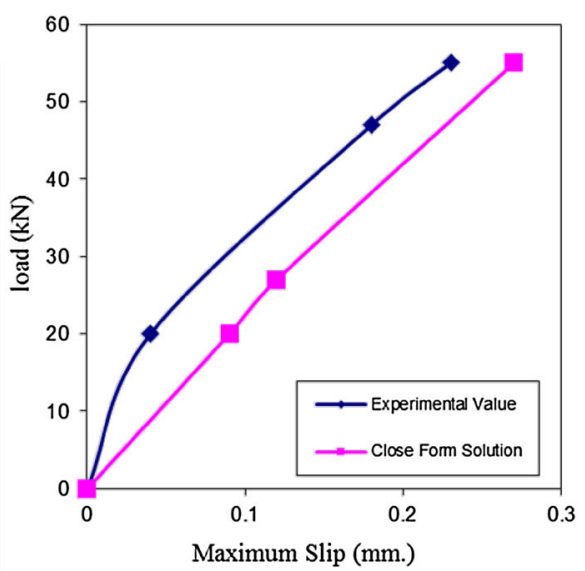

(e)

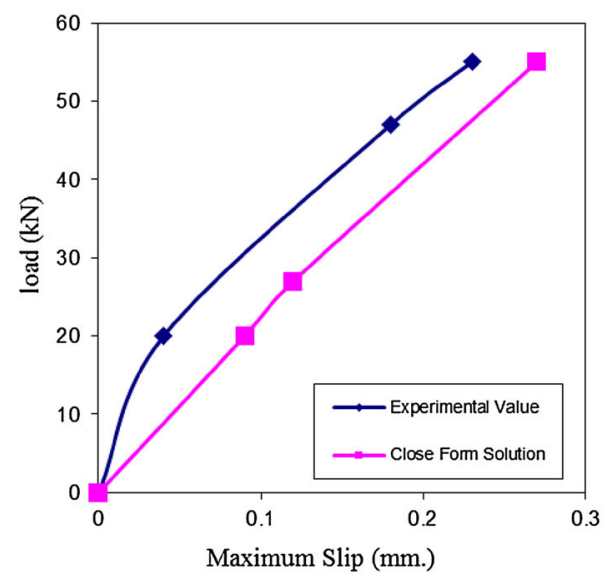

(b)

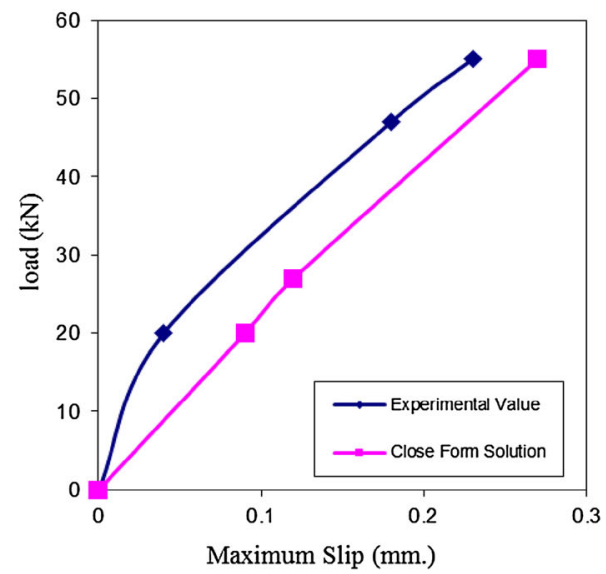

(d)

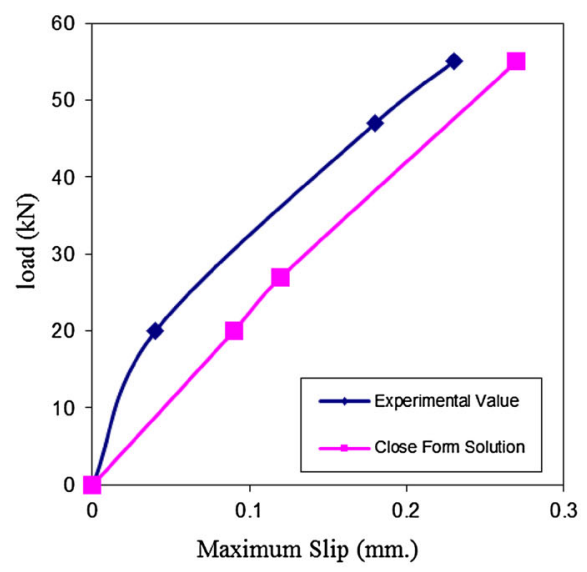

(f) intended to show their validity by comparing the results with the available experimental test results. Also, the effects of some parameters on the behaviour of simply composited beams are investigated. We also present a parametric study suggesting removal of the upper steel plate and comparing the results with two series which are encountered from literature survey. The first is by Roberts et al. in which nine pairs of rectangular beams are tested, details of which are given in Table 1 .

It can be seen from Fig. 3 that the presence of steel plate, at the underside of the beams, has the distinct effect of stiffening the beams, which reduces the deflection. 
The second series is by Abtan in which a series of 12 beams are tested, with details given in Table 2 .

All of the beams tested in each series had the same dimensions with simple supports, unequal reinforced concrete beam lengths and two external steel plates; they were loaded with a central point load. The calculated failure load of the tested beams in two series using theoretical models is given in Table 3. Predicted loads are in a close agreement.

The interface slip is the relative movement between the concrete beam and steel plate at the interface. For the series tested by Abtan, the calculated values of maximum slip are reasonably close to those observed by experiments. The mean ratios of the experimental to theoretical values are (1.01) and (0.99) and the standard deviation is (0.05) and (0.10), by closed form and numerical solutions, respectively. In addition, the distribution of slip along the beam is plotted in Fig. 4, which indicates that the maximum value of slip occurs at the end of the steel plate and becomes zero under the point load, at mid-span in the case of uniformly distributed load.

The maximum slip values are plotted against the applied load [up to the service load which is taken as (50\%) from the ultimate load] and shown in Fig. 5. It can be seen that

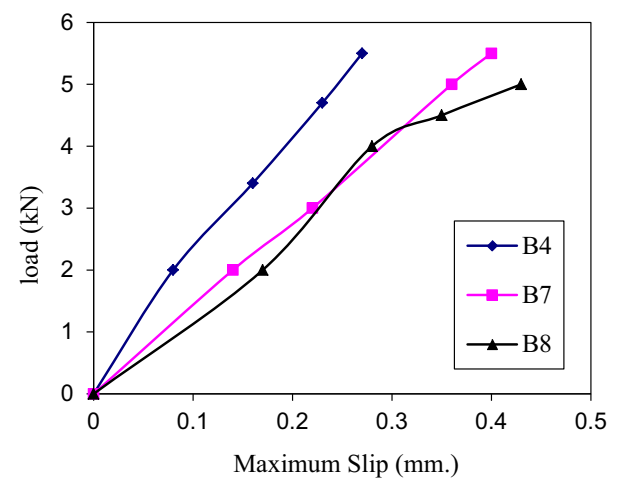

Fig. 6 Load-slip curve of typical beams the initial value of slip is noticed at (24-30\%) of the service load, with the increased value at the increased loading. When the slip is increased, loss of interaction results, allowing for extra deflection, whereas the slip is a function of the degree of connection and the properties of materials.

To isolate the effect of plate length, three beams are compared, which have one plate thickness and variable plate length, and in which all other parameters are kept constant. These three beams consist of beams (B4), (B7) and (B8) with a constant plate thickness $(3 \mathrm{~mm})$ and varying length of $(95 \%),(73 \%)$ and $(54 \%)$, respectively (see Fig. 6).

Figure 6 shows the load-maximum slip curve for the tested beams. It can be concluded that beams with shorter steel plates exhibit higher slip values at the concrete-steel interface and the increase in maximum slip is proportional to the increase in the length of steel plate.

It can be seen from Figs. 6 and 7 that the presence of steel plate, at the underside of the beams, has a distinct effect on the stiffening of the beams, which reduces the deflection.

The central deflection values for tested plated beams are very close to the predictions from the literature. The mean value of the ratios of experimental to theoretical central deflection is (1.02) and the standard deviation is (0.08), as given in Table 3.

\section{Conclusion}

A theoretical model has been presented herein to predict the deflection values for sandwich beams with two external steel plates. The limitation has been introduced in the sectional area of the steel plate provided in the tension and compression faces of the beam, which is based on the derived balanced area in order to prevent compression failure of the composite section. Also formulated equations indicate the
Fig. 7 Load-deflection curve. a For beam B3. b For beam B8

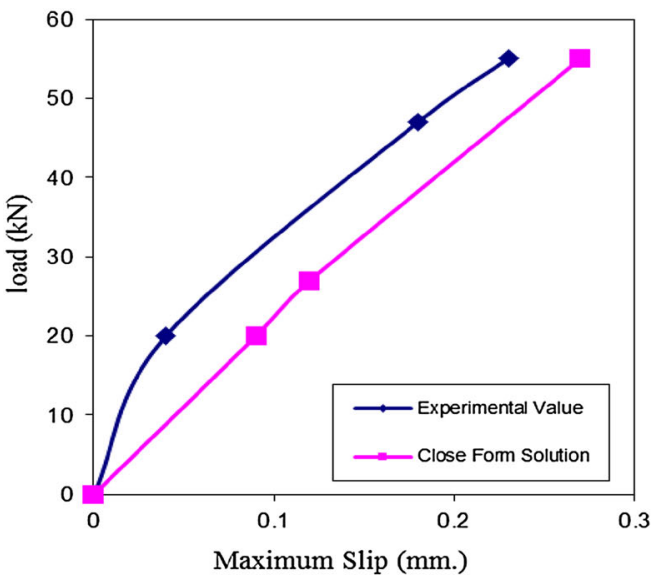

(a)

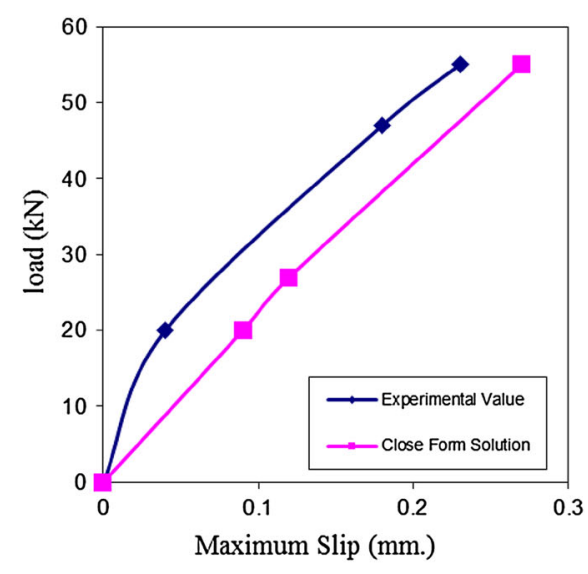

(b) 
behaviour of reinforced concrete beams strengthened with external steel plates, and have been applied to two test series, from literature, to examine the ability and efficiency of them in predicting the deflection. A close agreement is obtained showing that the solution is applicable to a wide range of beams.

The values of central deflection of beam influenced by the area and the length of the attached steel plates and beams, it appears that longer steel plates will fail at higher loads, as the length of the beam with composite section is increased, resulting in stronger sections.

It can be concluded that beams with shorter steel plates exhibit higher slip values at the concrete-steel interface and the increase in maximum slip is proportional to the increase in the length of steel plate.

Open Access This article is distributed under the terms of the Creative Commons Attribution 4.0 International License (http://crea tivecommons.org/licenses/by/4.0/), which permits unrestricted use, distribution, and reproduction in any medium, provided you give appropriate credit to the original author(s) and the source, provide a link to the Creative Commons license, and indicate if changes were made.

\section{References}

Abbu M (2003) Behaviour and Strength of Multilayer Beam with Unequal Lengths Components. M.Sc. Thesis, University of AlMustansirya. Baghdad

Abtan YQ (1997) Strength and the behaviour of reinforced concrete beams with external steel plates. M. Sc. Thesis, Department of Civil Engineering, University of Al-Mustansirya, Baghdad
Aykac Sabahattin, Kalkan Ilker, Uysal Ali (2012) Strengthening of reinforced concrete beams with epoxy-bonded perforated steel plates. Struct Eng Mech 44(6):735-751

Demir A, Tekin M, Turali T, Bagci M (2014) Strengthening of RC beams with prefabricated RC U cross- sectional plates. Struct Eng Mech 49(6):673-685

Han QH, Xu J, Xing Y, Li ZL (2015) Static push-out test on steel and recycled tire rubber-filled concrete composite beams. Steel Composite Struct 19(4):843-860

Itani RY, Hoyle RJ, Morshed HM (1981) Experimental evaluation of composite action. J Struct Div 107(3):551-565

Jones R, Swamy RN, Ang TH (1982) Under- and over-reinforced concrete beams with glued steel plates. Int J Cem Comp Light Con 4(1):19-32

Lezgy-Nazargah M, Kafi L (2015) Analysis of composite steelconcrete beams using a refined high-order beam theory. Steel Composite Struct 18(6):1353-1368

Ovigne PA, Massenzio M, Jacquelin E, Hamelin P (2003) Analytical model for the prediction of the eigen modes of a beam with open cracks and external strengthening. Struct Eng Mech 15(4):437-449

Roberts TM, Haji-Kazemi H (1989) Strengthening of under-reinforced concrete beams with mechanically attached steel plates. Int J Cem Com Light Con 11(1):21-27

Yang SH, Cao SY, Gu RN (2015a) New technique for strengthening reinforced concrete beams with composite bonding steel plates. Steel Composite Struct 19(3):735-757

Yang Y, Yu Y, Guo Y, Roeder CW, Xue Y, Shao Y (2015b) Experimental study on shear performance of partially precast Castellated Steel Reinforced Concrete (CPSRC) beams. Steel Composite Struct 21(2):289-302

Zhou W, Jiang L, Huang Z, Li S (2016) Flexural natural vibration characteristics of composite beam considering shear deformation and interface slip. Steel Composite Struct 20(5):1023-1042

Zou GP, Xia PX, Shen XH, Wang P (2016) Investigation on the failure mechanism of steel-concrete steel composite beam. Steel Composite Struct 20(6):1183-1191 